\title{
Experiência e movimento: pensando a educação em Dewey
}

\section{Experience and movement: thinking education in Dewey}

\author{
"Pensar é um ato, sentir é um fato". \\ (Clarice Lispector) \\ Celso llgo Henz ${ }^{*}$ \\ Cláudia Aparecida dos Santos* \\ Patrícia Signor $^{* * *}$
}

\section{Resumo}

Este artigo intenta aproximar-se do pensamento deweyano, com base nos pressupostos da teoria lógica apresentada pelo autor, especialmente no que tange à noção de conhecimento enquanto experiência. A pragmática deweyana assume, assim, especial interesse, quando situa as formas de pensar e conhecer como um traço distintivo do homem, em que o conhecimento só pode se tornar significativo quando suscita experiências para o indivíduo. Interessa, ainda, a ideia de movimento como eixo central de um processo formativo de caráter contínuo e inconcluso, capaz de gerar aprendizagens contextualizadas para compor uma escola ativa. Ao oferecer a possibilidade de uma aprendizagem significativa, quer seja para pensar o indivíduo, a sociedade ou a educação, a concepção educacional apresentada propõe a quebra de paradigmas e a transformação da escola e o faz justamente por compreender a educação como componente cultural significativo para a produção de liberdade.

Palavras-chave: Educação. Experiência. John Dewey. Movimento.

\section{Abstract}

This article tries to approach the Deweyian thought, to the presuppositions of the logical theory presented by the author, especially with regard to the notion of knowledge as experience. The pragmatic Deweyan, assumes special interest when he situates the ways of thinking and knowing as a distinctive feature of man, where knowledge can become meaningful only when it gives rise to experiences for the individual. As well as the idea of movement as the central axis of a formative process of continuous and inconclusive character, capable of generating contextualized learning to compose an active school. By offering the possibility of meaningful learning, whether to think about the individual, society or education, the presented educational conception proposes to break paradigms and the transformation of the school, and does so precisely because it understands education as a significant cultural component for the production of freedom.

Keywords: Education. Experience. John Dewey. Movement.

Recebido em 02/06/2017 - Aprovado em 09/11/2017

http://dx.doi.org/10.5335/rep.v25i1.8036

Doutor em Educação pela Universidade Federal do Rio Grande do Sul (2003). Professor Associado II da Universidade Federal de Santa Maria e pesquisador do Programa de Pós-Graduação em Educação, na linha de pesquisa: Formação, Saberes e Desenvolvimento Profissional. E-mail: celsoufsm@gmail.com

* Doutoranda em Educação, LP4 Educação e Artes, na Universidade Federal de Santa Maria (UFSM). Mestre em Educação pela Universidade Comunitária da Região de Chapecó (Unochapecó). Membro do Grupo de Estudos e Pesquisa em Arte, Educação e Cultura (Gepaec-UFSM). E-mail: claudiasartes@yahoo.com.br

*** Doutoranda em Educação na Universidade Federal de Santa Maria, na linha de pesquisa: Formação, Saberes e Desenvolvimento Profissional. Professora da educação básica e do ensino superior. Participa do grupo de estudos e pesquisas Dialogus: Educação, Formação e Humanização com Paulo Freire, registrado no Conselho Nacional de Desenvolvimento Científico e Tecnológico (2011). E-mail: psignor89@gmail.com 


\section{Introdução}

Em cada momento histórico, concepções pedagógicas de ensino-aprendizagem orientam as práticas socioculturais, visando à formação dos sujeitos para a vida. $\mathrm{Na}$ contemporaneidade, a emergência de pensar uma educação correlata ao nosso tempo justifica o porquê lançamo-nos no desafio de pensar a validade das noções de experiência e movimento em Dewey, como formas de refletir a contingência dos novos paradigmas que circunscrevem nosso tempo.

As ideias capturadas em Dewey (1979) expressam a valorização do ato de pensar como elemento definidor do homem. E isso interessa nesta discussão, posto que o pensamento emancipa o indivíduo das ações meramente impulsivas e rotineiras. Segundo o autor, é pelo pensamento que o homem é capaz de projetar suas atividades, escolher seus percursos, modificar-se e produzir-se conscientemente.

Dewey explica, na obra Como pensamos (1979), que os indivíduos aprendem mediante o enfrentamento de situações problemáticas que lhes acometem no curso das atividades. Para ele, o pensamento compõe uma função mediadora e instrumental, que serve como suporte fundamental à sobrevivência e ao bem-estar humanos em diferentes tempos.

Ao longo de sua carreira, John Dewey ${ }^{1}$ desenvolveu uma filosofia; a exemplo de sua própria ação, como intelectual e militante político, dedicou-se ao desenvolvimento de uma teoria do conhecimento, que questionava os binarismos: mente e mundo físico, pensamento e ação, teoria e prática, visando, desse modo, romper com a epistemologia dualista que abalizava a filosofia ocidental desde o século XVII. Mormente, dedicou sua vida ao aperfeiçoamento de uma convicção moral, ao afirmar: a "democracia é liberdade" (DEWEY, 1959).

A pragmática deweyana assume especial interesse na construção deste artigo, quando situa as formas de pensar e conhecer como um traço distintivo do homem. E fá-lo justamente por compreender a educação como componente cultural significativo para a produção de liberdade. Posto que, para o autor: "A verdadeira liberdade [...] é intelectual [...]", e esta "[...] reside no poder do pensamento exercitado, na capacidade de 'virar as coisas ao avesso', de examiná-las deliberadamente [...]" (DEWEY, 1979, p. 96).

Em Dewey, o pensamento é entendido como um esforço consciente e voluntário, que se inicia pela observação e, consecutivamente, dá-se pela ordenação de hipóteses com necessárias intervenções, constituindo-se em instrumento destinado a resolver problemas.

Na primeira parte da obra Como pensamos, Dewey (1979) explica que o pensamento reflexivo é a investigação que tem por objetivo cunhar uma situação nova, 
clara, coesa e harmônica, onde antes existia confusão ou obscuridade. ${ }^{2}$ Para o autor, a "melhor" maneira de pensar poderia ser denominada de "pensamento reflexivo". Explica, pois: refletir corresponde ao ato de "examinar mentalmente o assunto e dar-lhe consideração séria e consecutiva” (DEWEY, 1979, p. 13). Portanto, a ação reflexiva implica uma consideração ativa, persistente, em que "[...] um estado de dúvida, hesitação, perplexidade, dificuldade mental" é sucedido por "[...] um ato de pesquisa, procura, inquirição, para encontrar material que resolva a dúvida, assente e esclareça a perplexidade" (1979, p. 22). Nessa passagem, evidencia-se o caráter processual desse modo de pensamento, em que a noção de movimento torna-se central no pensamento de John Dewey. Nessa perspectiva, que se sabe teórico-prática, um princípio firmado não é o mero registro de algo acabado, mas percurso para adentrar experiências futuras, que também devem ser "postas a prova" num continuum.

A escola nova cunhada por Dewey apresenta grande potencial à promoção da autonomia dos educandos, pois dá espaço privilegiado às experiências enquanto caminho para a produção do conhecimento. Tal perspectiva mostrou-se inovadora em relação ao modelo tradicional, cujo foco centrava-se na memorização de conhecimentos dogmáticos. A pedagogia deweyana, pautada na noção da liberdade de pensamentos e atitudes, no estímulo ao uso da racionalidade e do pensamento crítico, além da valorização do potencial da criança, converge, em certa medida, com a proposta kantiana (KANT, 1985), quando convoca para o "esclarecimento" dos sujeitos, ou seja, convida a sair da "menoridade intelectual", soa assim como um chamado para aprender a pensar por conta própria.

Reconhecemos, assim, a pertinência de Dewey, ainda na atualidade, na problematização e na transformação do status quo. Damos ênfase à concepção educacional apresenta pelo autor, seja por sua acentuada influência na educação norte-americana, seja no Brasil, no período do movimento da Escola Nova, cujas ideias foram apresentadas por Lourenço Filho e Anísio Teixeira, e fazemo-lo por entender que a educação pública precisa, cada dia mais, de pessoas engajadas no árduo propósito da transformação social em busca de qualidade da educação, garantindo o acesso e a permanência dos estudantes na escola, bem como a democratização do conhecimento e da gestão, para que realmente seja um direito e uma conquista de todos e de todas.

Julgamos que Dewey foi e ainda é um importante nome no que se refere à Educação, e suas ideias continuam pulsando no discurso educacional brasileiro. Segundo Gadotti (1996), Dewey preocupou-se com o papel da democracia na esfera social, em sua organização, dedicando especial atenção à defesa da escola pública. Nesse aspecto, sua teoria não pode ser datada, nem alocada territorialmente, 
transpassando a barreira espaço-temporal e sendo de grande valor ainda na atualidade, em um contexto educacional como o brasileiro.

No outono de 1894, Dewey escreveu à esposa Alice: "Às vezes penso que deixarei de ensinar Filosofia diretamente, para ensiná-la por meio da pedagogia" (1894 apud WESTBROOK et al., 2010, p. 11-12). Em sua fala transparece a importância que dava para a educação, correspondente ao papel de educar. Mas, mais importante que a escola como campo de experimentação (da Psicologia Funcional e do pragmatismo), tem-se a expressão ética como proposta de uma teoria democrática encontrada em suas obras. Para o autor, o ponto primordial concentra-se na função social da educação. O movimento realizado por Dewey entende a escola enquanto espaço ativo, e nele o conhecimento deve ser incentivado pelo professor. Para que seja possível que crianças e jovens construam sua identidade em diferentes tempos e espaços, um dos contextos em que eles precisam participar corresponde aos espaços de construção política da democracia, tanto nas decisões quanto na elaboração de planejamentos e na fiscalização do trabalho de nossos representantes. Uma vez que a educação para a democracia promove (ou pode promover) a conversão da escola em "[...] uma instituição que seja, provisoriamente, um lugar de vida para a criança, em que ela seja um membro da sociedade, tenha consciência de seu pertencimento e para a qual contribua" (DEWEY, 2010, p. 224).

Por esse viés, ao perspectivar a estreita e essencial relação entre a necessidade de filosofar e a necessidade de educar, Dewey revela-se um pensador preocupado com a compreensão da realidade. Podemos dizer que, mormente, a escola de Dewey apresentava-se como um experimento de educação para a democracia. O teórico defendia que a educação deveria ser, antes de qualquer outra coisa, fator de humanização e transformação social. ${ }^{3}$ Assim, compreendemos a atualidade de Dewey, quando este desenvolveu teorias pedagógicas, particularmente em relação à inserção do estudante como sujeito de experiência no processo de aprendizagem.

\section{Experiência e pertencimento como proposta de ensino}

Por um período muito longo, segregou-se o direito à educação. Para muitos sujeitos, "Não apenas foi negado e dificultado seu acesso ao conhecimento produzido, mas foram despojados de seus conhecimentos, culturas, modos de pensar-se e de pensar o mundo e a história" (ARROYO, 2013, p. 14). Esses grupos, alocados à margem da sociedade intelectual, continuaram a servir e a ocupar posições de subserviência física, laboral e intelectual. E, ainda, mesmo quando conquistaram o direito de chegar à escola, esta se mostrou despreparada à sua formação. A lacuna social é histórica e, infelizmente, perdura até os dias de hoje, ao menos no Brasil. ${ }^{4}$ 
No campo educacional, nota-se que a projeção destas construções "naturalizadas" como legítimas, provenientes de fontes diversas, como políticas públicas, postulados cientificistas, preconceitos, herança cultural externa, etc., impostas como balizas para a organização curricular das escolas, perpetua a construção de enredos seletivos e diretivos, em que o "nós" é anunciado como hegemônico. E o outro “[...] é apresentado em posição de subordinação - pela qual há de ser civilizado e, portanto, justificadamente explorado e despojado de seus saberes" (HERNÁNDEZ, 2007, 13).

Quando uma criança é condicionada a esquecer-se do que já sabe e orientada a afastar-se do que conhece, para assumir comandos e conceitos que lhe soam abstratos, não sendo possível (re)significar esses conteúdos para a vida no convívio da família e de sua comunidade, há um empobrecimento dos saberes. Considera-se, por esse viés, urgente mudar a maneira de conceber a produção de conhecimento.

Neste jogo de educar pela comunicação, instaura-se um fluxo de experiência transformadora, em que os agentes envolvidos, quem recebe e quem comunica, imperativamente, transformam-se de certo modo. Por conseguinte, privilegiar os espaços de participação e diálogo nas escolas é valorar a capacidade e as vivências de estudantes e professores em nome de engajá-los como protagonistas da instituição e da comunidade da qual fazem parte, concebendo o diálogo como fundamental para a democratização da sociedade e a participação dos sujeitos na construção da realidade.

A concepção de experiência transformadora na educação é processual, uma vez que:

[...] envolve a formação de atitudes tanto emocionais, quanto intelectuais; envolve toda nossa sensibilidade e modos de receber e responder a todas as condições que defrontamos na vida. Desse ponto de vista, o princípio de continuidade de experiência significa que toda e qualquer experiência toma algo das experiências passadas e modifica de algum modo as experiências subsequentes (DEWEY, 2010, p. 26).

Por isso, acenamos para a ideia de "movimento", na qual tudo está em mutação contínua. Compreende-se, por conseguinte, a educação como processo em que "[...] o método, o objetivo e a compreensão do trabalho" estejam "[...] presentes na consciência do realizador do trabalho e que sua atividade tenha significado para ele" (DEWEY, 2010, p. 16). Podemos definir, nessa perspectiva teórico-prática, a educação como um processo de reconstrução e reorganização da experiência, ponto em que se adensam os sentidos produzidos.

A passagem supracitada parece um oportuno passo à orientação do trabalho pedagógico, uma vez que oferece como possibilidade "levar a criança para além" da aquisição estática de certos modos de ação, antes devendo modificar "[...] seu 
estímulo interno e sentindo, como próprio, o sucesso ou o fracasso da atividade" (WESTBROOK et al., 2010, p. 44).

Sem dúvida, tal mobilidade remete à luta por um currículo pensado coletivamente, que produza sentidos aos sujeitos envolvidos. Aliás, ainda há que se levar na devida conta o cenário que se instaura, no qual as relações e construções humanas se dão cada vez mais problemáticas. Portanto, uma educação efetiva, conectada às realidades, arquitetada a partir de seus contextos, remonta à conquista de um modo de agir. Para Dewey, é nesse sentido que toda educação é social.

A noção de movimento defendida está muito próxima do entendimento de participação como fator imprescindível à educação. Dessa forma, a participação é entendida como ação - que leva à conquista de autonomia dos sujeitos educandos.

Um importante passo no caminho para pensar a escola de modo mais humanizado é o reconhecimento da liberdade e da capacidade intelectual de crianças e jovens de nossas escolas, bem como o trabalho voltado para a realidade destas. Uma escola constituída por quem não olha conjuntamente desperdiça diariamente sonhos, vidas e experiências, que poderiam tornar o mundo mais sensível. Ao passo que a escola se abre para o público atual e que antes estava fora dali, abre-se também para a utopia de concretizar um novo projeto de sociedade, com histórias diferentes para caminhos até hoje condenados à inalterabilidade.

A partir de Dewey, compreende-se que os estudantes não chegavam à escola como lousa limpa, sobre a qual os professores escrevem. Quando a criança chega à escola, ela "[...] já é intensamente ativa e a incumbência da educação consiste em assumir a atividade e orientá-la" (DEWEY, 1979, p. 25). A necessária valorização dos saberes prévios tem muito a acrescer na construção dos saberes e das experiências cotidianas das escolas públicas. Tal incumbência passa por admitir que é possível conduzir os rumos da educação e dar outros sentidos às aprendizagens.

Em um século marcado por modificações intensas na ciência, na tecnologia, no trabalho, na cultura e na vida em sociedade, é necessário cunhar na dinamicidade da educação caminhos e alternativas que permitam aos sujeitos aprender e se "modificar". Em Dewey, isso se viabiliza pela experiência do educando. Sublinhamos que a ênfase não está nos resultados do pensar, mas no processo em si, enquanto método para organizar o pensamento. O autor diferencia "o treino", uma forma preliminar e incompleta de educação, do que entende por educação verdadeira; afirma que nada se ensina, nem se aprende, se não pela compreensão comum, se não pela experiência (DEWEY, 2002, p. 71).

Aproximamo-nos, assim, do conceito de experiência em seu aspecto ativo. Toda experiência se dá como um processo contínuo de criação e de conexões. Fundamentalmente, é a experiência que permite transformações nas relações do homem com o meio que o circunda. 
Dessarte, a pedagogia de Dewey $(2002,2010)$ solicita que os educadores realizem a tarefa de reincorporar os temas de estudo na experiência. A postura participativa e interativa do professor, dentro do processo, faz com que ele também ganhe maior reconhecimento em seu trabalho de preparação e condução das aulas, comprometendo-se com a construção de um ambiente em que as atividades imediatas dos alunos sejam confrontadas com situações problemáticas do cotidiano, cuja resolução exija conhecimentos teóricos e práticos de diversas esferas, científica, histórica, artística, etc.

Ademais, a teoria educativa de Dewey dá grande relevo ao papel do educador, o que se evidencia por sua convicção de que cabe à escola, tal como a concebe, a incumbência de inculcar no educando uma faceta moral, democrática, lógica. A mensagem de Dewey aos educadores paira sobre o compromisso assumido com a docência:

[...] compete a você (educador) conseguir que existam as condições que estimulem e desenvolvam, todos os dias, as faculdades ativas de seus alunos. Cada criança há de realizar seu próprio destino tal como se revelam a você os tesouros das ciências, da arte e da indústria (DEWEY, 2002, p. 291, grifo nosso).

O fragmento aponta para maior autonomia e responsabilidade dos recursos teóricos e psicológicos para organizar o trabalho docente, indo ao encontro da construção de uma educação integral, que contribua para o crescimento físico, emocional e intelectual. $\mathrm{O}$ autor também teceu severas críticas em relação às escolas que não permitiam a participação dos professores nas decisões e no aprimoramento da educação pública.

Ainda na direção de compreender o arcabouço teórico que fundamenta a pedagogia nova de Dewey, fazendo um contraponto ao modelo escolar tradicional, tem-se outro conceito de escola, que, segundo Teixeira, "[...] não deve ser a oficina isolada onde se prepara o indivíduo, mas o lugar onde, numa situação real de vida, indivíduo e sociedade constituam uma unidade orgânica" (1973, p. 28). A partir de Dewey, a aprendizagem deve estar baseada na resolução de problemas. O projeto deweyano concebe as escolas como uma "comunidade embrionária", que espelha a vida social como um todo, e esta deve estar "impregnada do espírito da arte da história e da ciência" (DEWEY, 2002, p. 35). Para o autor, a imposição de "cima para baixo" contraria a expressão e o cultivo da individualidade; devendo aproveitar ao máximo as oportunidades do presente. Por isso sua insistência para que a escola fosse compreendida muito mais próxima da vida da criança e não alheia a ela. Para explicar a questão, reportamo-nos à explicação dada na obra A escola e a sociedade: a criança e o currículo: 
[...] se a criança analisa o seu próprio impulso, tendo para isso de reconhecer os fatos, os materiais e as condições implicadas e, em seguida, usa esse reconhecimento para regular o impulso inicial, então sim, estamos na presença de um processo educativo. É esta a diferença, que desejo sublinhar, entre excitar ou satisfazer um interesse e canalizá-lo numa dada direção, propiciando sua análise (DEWEY, 2002, p. 44-45).

Percebe-se que a essência da pedagogia de Dewey está na defesa da liberdade, em que a aprendizagem passa invariavelmente pela experiência.

Freire (1987) também almejava uma forma de educar que ultrapassasse as barreiras de conteúdos e informações descontextualizados. Ele lutou pela superação da visão bancária do saber, pela transformação da escola fragmentada e distante dos sujeitos educandos, de aulas abstratas que não contemplam problemas cotidianos, políticos e sociais. Para Freire, “[...] os homens são capazes de agir conscientemente sobre a realidade objetivada" (1980, p. 26). Menciona, assim, o que chamou de "práxis humana", unidade indissolúvel, o que se arquiteta entre a ação e a reflexão sobre o mundo.

A “práxis humana” a que Freire (1980) e Freire e Horton (2003) se referem converte-se em conhecimentos, assim que o sujeito reflete, avalia e muda. Nesse processo natural, o sujeito vai se "humanizando" e tornando-se cada vez mais autônomo e, consequentemente, livre. Dewey (1959) e Freire se aproximam muito ao pensar a educação como uma das bases que conduzem os sujeitos a uma liberação do julgo externo. Dewey explica que: “[...] liberdade é poder de agir e executar, independentemente de tutela exterior" (1959, p. 93). De acordo com ambos os autores, é por meio da educação que o homem pode desenvolver-se, e a escola deve garantir a formação de competências lógicas e disciplinadas de pensar.

$\mathrm{Na}$ recepção da influência de Dewey em Freire, sublinhamos, de forma particular, o entendimento de ambos acerca do compromisso da educação com o "pensar" autônomo. Entende-se que a escola exerce o importante papel de propiciar condições para esse protagonismo, enquanto instituição que acolhe e garante acesso aos jovens de todas as esferas públicas, classes sociais, comunidades, culturas, credos e estilos de viver. Sendo assim, a escola que se faz verdadeiramente "democrática" tem em si um enorme potencial para garantir que os educandos se sintam, além de acolhidos, sujeitos de um processo de formação integral, com qualidade social, garantia de equidade e chances para explorar novos caminhos.

Devemos admitir que tamanho esforço já teve seu início em muitos lugares do país. Contudo, ainda encontra resistência em formulações diretivas e em políticas públicas, que impõem às escolas priorização de conteúdos e posturas taxativamente tradicionais. Uma educação que não olha para seus sujeitos é uma educação morta, vazia. Assim sendo, não há razão para que ela exista, já que não provoca para o novo e não constrói uma relação de reciprocidade, pertencimento e liberdade. 
Com efeito, "Não se educa diretamente, mas indiretamente pelo meio social" (WESTBROOK et al., 2010, p. 45), na correlação entre os conteúdos tratados em sala de aula e o meio que circunda os educandos. O que se tem em mãos é a possibilidade da criação de condições adequadas, que permitam que a educação aconteça. Afinal, os professores não podem impor seus conhecimentos para os alunos. Dewey (2002) ressalta a importância do professor no exercício de construir uma contextualização consistente, criando oportunidades para a compreensão a partir das experiências dos estudantes, e diz que o ensino deve estar vinculado à lógica do aluno. Deve-se criar um ambiente em que os sujeitos assumam, por si mesmos, por via da experiência, os encargos de uma vida moral e democrática. Uma interrogação de Dewey ajuda a entender o sentido que ele dá à democracia:

Que significa a democracia se não todas as pessoas participando da determinação das condições e objetivos de seu próprio trabalho e que, definitivamente, graças à harmonização livre e recíproca das diferentes pessoas, a atividade do mundo se faça melhor, do que quando poucos planejam, organizam e dirigem, por mais competentes e bem intencionados que sejam estes poucos? (WESTBROOK et al., 2010, p. 233).

Atentemos para a noção de "participação" na passagem supracitada: "Que significa a democracia se não todas as pessoas 'participando' [...]”, a conjugação do verbo reverbera como movimento-ação, que compreende em si os sujeitos enquanto agentes ativos do processo democrático. Já que se traduz na adesão "voluntária" e no desejo de participar para modificar atitudes anteriores, comporta em si uma natureza formativa, levando à dimensão coletiva de vida social, o engajamento pode estar relacionado ao estímulo para novas aprendizagens e à motivação por um reconhecimento enquanto atores de um processo de construção social democrática, que promove o desenvolvimento da argumentação e de posicionamentos acerca dos rumos da sociedade.

Assim, a participação é vista como parte do processo educativo, que potencializa as aprendizagens e fortalece os jovens e a escola. A dimensão ativa da participação na formação educacional problematiza o papel da instituição escolar na composição da democracia para a vida pública e para o exercício da cidadania. Sem dúvida, há uma intrínseca relação entre os estudantes em formação e a participação enquanto processo constitutivo, sendo possível apontar a escola como um locus em que se exerce a cidadania.

Conforme Dayrell e Carrano, cabe à escola avançar muito nesse sentido:

É uma tendência da escola não considerar o jovem como interlocutor válido na hora da tomada de decisões importantes para a instituição. Muitas vezes, ele não é chamado para emitir opiniões e interferir até mesmo nas questões que dizem respeito a ele, diretamente. E isso, sem dúvida, pode ser considerado como um desestímulo à participação e ao protagonismo (2014, p. 106). 
A instituição escolar não pode se contentar em ministrar aulas dentro de salas, isolada dos contextos que a todo instante lhe batem à porta e interferem diretamente na vida dos sujeitos educandos. Freire, ainda a esse respeito, assevera: "Se não é possível defender uma prática educativa que se contente em girar em torno do 'senso comum' [...]", também não é possível aceitar que a prática educativa “[...] parta do conhecimento sistematizado do(a) educador(a)" (1992, p. 59).

Concordamos com Dewey e Freire quando dizem que a finalidade da educação é formar indivíduos livres, autônomos e capazes de adaptar as condições do ambiente a seu favor. Assim, o cultivo do pensamento reflexivo corresponde ao crescimento da liberdade individual, que, neste caso, dá-se como efeito da educação como processo.

$\mathrm{Na}$ ótica assumida neste texto, a escola é tempo e espaço para desenvolver, nos jovens, a consciência do papel social e político da educação, resistir a práticas repressoras dentro da sala de aula e, principalmente, fora dela. Problematizar, questionar e buscar in loco o conhecimento da realidade cultural, econômica e social do lugar em que se vive são desafios constantes no processo de conscientização sobre a realidade.

\section{Considerações finais}

Diante da linha teórica abordada neste artigo, observamos-se que a concepção educacional deweyana oferece, ainda nos dias atuais, contribuições à formação dos sujeitos. Uma das ideias basilares do pensamento de Dewey está na educação enquanto fator de humanização e transformação social por meio de práticas integradas ao cotidiano, realizadas pelos professores, pelos estudantes e pela comunidade, enquanto atores e sujeitos de sua própria formação e construção do conhecimento.

$\mathrm{Na}$ teoria desenvolvida por Dewey, os educandos têm liberdade para elaborar aprendizagens, a partir de suas escolhas, (re)significando também o papel do educador, enquanto mediador que reconhece as situações concretas de aprendizagens e oportuniza a produção de conhecimentos relevantes aos educandos e à própria prática docente como meio de desenvolvimento de uma sociedade mais democrática. Compreendemos, assim, que o pensamento reflexivo é caro à teoria apresentada e corresponde à chave para exercitar a capacidade de raciocínio e espírito crítico dos estudantes, em que a aprendizagem se dá instigada pelas situações-problema, marcada pela prática e pela construção de conhecimento enquanto processo.

O teórico revolucionou pela forma que compreendeu a produção do conhecimento, opondo-se ao ensino tradicional em vigor. Propôs uma aprendizagem instigada pelos problemas vividos pelos estudantes. Assim, partir das dúvidas e 
perturbações, educadores e educandos poderiam promover mudanças e soluções criativas. Está claro, no anunciado por Dewey, que é do educador a responsabilidade de pesquisar, orientar, interpretar, avaliar, acompanhar e contribuir com as aprendizagens de seus alunos, exigindo-lhes disponibilidade e colaboração no processo de aprendizagem e competência para lidar com situações imprevistas e desconhecidas, compartilhando saberes para que ambos construam e reelaborem conhecimentos.

Para Dewey, o conhecimento só pode se tornar significativo quando compõe experiências para o indivíduo, por isso, incentiva a autonomia e a liberdade de crianças e jovens na escola, esta pensada enquanto espaço de diálogo, vivências e possibilidades para novas e coletivas aprendizagens. No cotidiano escolar, essas aprendizagens seriam aproveitadas enquanto experimentação de possibilidades individuais e coletivas, visando ao crescimento e ao desenvolvimento dos estudantes de maneira crítica e consciente de suas capacidades.

Ao propor a mudança no processo educativo, Dewey também lançou inúmeros desafios à estrutura social e histórica da escola, rompendo com os modelos tradicionais de formação de profissionais e de currículos escolares, nos quais cabia unicamente ao professor a transmissão de saberes historicamente acumulados, e aos alunos, o papel de decorar e reproduzir conceitos que, na maioria das vezes, estavam descolados de sua compreensão de mundo e de suas vivências culturais. Ao oferecer a possibilidade de uma aprendizagem significativa, o movimento da Escola Nova propõe a quebra de paradigmas e a transformação da escola, como instituição geradora de movimentos, que compreende diferentes realidades sociais e que, até hoje, influencia as propostas curriculares e a estrutura escolar mundial.

Os argumentos interpelados qualificam a produção deste texto e ampliam a compreensão de que uma educação que acolhe em seu seio as especificidades humanas, na produção de conhecimento enquanto processo, agindo pela promoção da vida, se faz necessária atualmente. A escola, enquanto instituição educativa, precisa promover a democracia e contribuir para a conscientização do ser humano de seu espaço e papel ao arquitetar estruturas menos injustas e mais cooperativas.

Construir uma escola mais humana e democrática exige de seus educadores a sensibilidade de reconhecer os interesses e anseios dos estudantes (uma vez que, para Dewey, a aprendizagem só é possível quando parte dos interesses e das experiências práticas dos sujeitos envolvidos). É pela vivência e pela experiência que o homem produz significados para aquilo que lhe é transformador.

Dewey elegeu o pensamento reflexivo como imprescindível ao processo de aprendizagem, já que acreditava que a aprendizagem é como um traço que se inscreve por si mesmo na e pela experiência. Destacamos, ainda, a tênue relação entre 
experiência e produção de pensamento, que compreendemos como eixo capaz de afiançar, nas esferas sociais e, sobretudo, nos sujeitos, o protagonismo das ações e, consequentemente, a liberdade. Referimo-nos ao "pensamento exercitado", que aumenta a capacidade de examinar deliberadamente uma determinada situação independente de tutela exterior (DEWEY, 1979). A experiência, por essa perspectiva, perfaz-se como exercício para o pensamento.

Em última instância, percebe-se como escopo da educação deweyana o aprimoramento da vida social consubstanciada pela democracia. Assim, pensamos a aprendizagem pela experiência enquanto abalo e transformação das organizações sociais sedimentadas, em que se olha a educação de perto, a partir das necessidades coletivas e individuais, como forma de produção de saberes verdadeiramente significativos.

\section{Notas}

1 John Dewey foi o filósofo norte-americano mais importante da primeira metade do século XX. Seu compromisso com a democracia e com a integração entre teoria e prática concede-lhe o status de reformador da educação, sendo um importante nome ao se refletir acerca do contexto educacional também na atualidade.

2 Sublinhamos que o termo reflexivo, enquanto conceito, encontra ressonância nas ideias do filósofo, psicólogo e pedagogo norte-americano John Dewey (1859-1952). Ao caracterizar o pensamento reflexivo, Dewey destaca três atitudes que favorecem a ação reflexiva: abertura de espírito, responsabilidade e empenho.

$3 \mathrm{Na}$ ótica deste teórico, a educação é entendida como instrumento a serviço da democratização, contribuindo para vivências comunitárias dos grupos sociais, no diálogo, para formar pessoas participantes. A reforma da educação e a reforma da sociedade andam juntas, sendo parte do mesmo processo.

4 Em janeiro/fevereiro de 2003, a Revista Escola, publicou algumas ideias a respeito de Dewey; o artigo intitulado "Atual há 100 anos" apresenta a importância do autor no cenário educacional. Em 2010, a Revista Educação, na edição de dezembro, dedicada à "História da pedagogia", também deixa notar a importância do pensamento deweyano. No próprio editorial, a professora da Universidade de São Paulo Teresa Cristina Rego conclui: "Espero que a leitura deste número instigue a curiosidade do leitor e o convide a fazer o estudo cuidadoso de uma obra que ainda tem muito a nos dizer no século XXI" (2010, p. 5).

\section{Referências}

ARROYO, Miguel Gonzáles. Currículo, território em disputa. 5. ed. Petrópolis: Vozes, 2013.

BLOCH, Ernest. O princípio da esperança. Rio de Janeiro: Uerj; Contraponto, 2005.

DAYRELL, Juarez; CARRANO, Paulo. Juventude e escola. Juventude e ensino médio: quem é este aluno que chega à escola. In: DAYRELL, J.; CARRANO, P.; MAIA, C. L. (Org.). Juventude e ensino médio: sujeitos e currículos em diálogo. Belo Horizonte: Editora UFMG, 2014. Seção 2. p. 101-134.

DEWEY, John. Arte como experiência. São Paulo: Martins Fontes, 2010.

A escola e a sociedade: a criança e o currículo. Lisboa: Relógio D’água, 2002. 
. Como pensamos: como se relaciona o pensamento reflexivo com o processo educativo: uma reexposição. São Paulo: Companhia Editora Nacional, 1979.

Democracia e educação. São Paulo: Companhia Editora Nacional, 1959.

FREIRE, Paulo; HORTON, Myles. O caminho se faz caminhando: conversas sobre educação e mudança social. Petrópolis: Vozes, 2003.

FREIRE, Paulo. Pedagogia da esperança: um reencontro com a Pedagogia do oprimido. Rio de Janeiro: Paz e Terra, 1992.

. Pedagogia do oprimido. 11. ed. Rio de Janeiro: Paz e Terra, 1987.

. Conscientização: teoria e prática da libertação - uma introdução ao pensamento de Paulo Freire. São Paulo: Cortez, 1980.

GADOTTI, Moacir. História das ideias pedagógicas. São Paulo: Ática, 1996.

HERNÁNDEZ, Fernando. Catadores da cultura visual: proposta para uma nova narrativa educacional. Porto Alegre: Mediação, 2007.

KANT, Immanuel. Resposta à pergunta que é esclarecimento? In: Textos seletos. Trad. Raimundo Vier. Petrópolis: Vozes, 1985. p. 100-117.

REGO, Teresa Cristina. Na Contramão da Tradição. Revista Educação - História da Pedagogia: John Dewey. São Paulo: n. 6, p. 5, 2010.

WESTBROOK, Robert B. et al. (Org.). John Dewey. Recife: Massangana, 2010.

TEIXEIRA, Anísio Spinola. A pedagogia de Dewey. In: DEWEY, John. Vida e educação: (i) a criança e o programa escolar e (ii) interesse e esforço. Trad. Anísio Teixeira. 8. ed. São Paulo: Melhoramentos, 1973. p. 13-41. 